\title{
Ionic liquid modified carbon paste electrode and investigation of its electrocatalytic activity to hydrogen peroxide
}

\author{
ERHAN CANBAY, HAYATI TÜRKMEN ${ }^{\dagger}$ and EROL AKYILMAZ* \\ Department of Biochemistry, Faculty of Science, Ege University 35100 Bornova-Izmir/Turkey \\ ${ }^{\dagger}$ Department of Chemistry, Faculty of Science, Ege University 35100 Bornova-Izmir/Turkey
}

MS received 24 December 2012; revised 25 April 2013

\begin{abstract}
This paper reports on the preparation and advantages of novel amperometric biosensors in the presence of hydrophobic ionic liquid (IL), 1-methyl-3-butylimidazolium bromide ([MBIB]). Carbon paste biosensor has been constructed by entrapping horseradish peroxidase in graphite and IL mixed with paraffin oil as a binder. The resulting IL/graphite material brings new capabilities for electrochemical devices by combining the advantages of ILs composite electrodes. Amounts of $\mathrm{H}_{2} \mathrm{O}_{2}$ were amperometrically detected by monitoring current values at reduction potential $(-0.15 \mathrm{~V})$ of $\mathrm{K}_{3} \mathrm{Fe}(\mathrm{CN})_{6}$. Decrease in biosensor responses were linearly related to $\mathrm{H}_{2} \mathrm{O}_{2}$ concentrations between 10 and $100 \mu \mathrm{M}$ with $2 \mathrm{~s}$ response time. Limit of detection of the biosensor were calculated to be $3.98 \mu \mathrm{M}$ for $\mathrm{H}_{2} \mathrm{O}_{2}$. In the optimization studies of the biosensor some parameters such as optimum $\mathrm{pH}$, optimum temperature, enzyme amount, interference effects of some substances on the biosensor response, reproducibility and storage stability were carried out. The promising results are ascribed to the use of an ionic liquid, which forms an excellent charge-transfer bridge and wide electrochemical windows in the bulk of carbon paste electrode.
\end{abstract}

Keywords. Biosensor; ionic liquid; 1-methyl-3-butylimidazolium bromide; carbon paste electrode; horseradish peroxidase.

\section{Introduction}

Recently, electrochemical study of the third generation biosensor based on the direct electron transfer between the protein and the electrode has been widely investigated at various electrodes. The main aim is to elucidate the complex mechanisms of biological electron transfer and determine their potential application in biotechnology (Xu et al 2006; Gao et al 2007). Until now, horseradish peroxidase (HRP) is often used as the molecules for the study of electron transfer reactions because of their commercial availability, moderate cost, and known and documented structure (Chen et al 2000; Xiao et al 2000). However, direct adsorption of such proteins onto the electrode surface can frequently result in their denaturation and the loss of bioactivity (Liu et al 2006). Therefore, it is necessary to develop new immobilization methods to realize direct electrochemistry without loss of the bioactivity of protein.

Carbon paste electrode (CPE), which was made up of carbon particles and organic liquid, has been widely applied in the electroanalytical community due to its low cost, ease of fabrication, high sensitivity for detection and

\footnotetext{
*Author for correspondence (erol.akyilmaz@ege.edu.tr)
}

renewable surface (Wang and Lu 1998; Kulys 1999). However, carbon paste electrodes (CPEs) also exhibit several disadvantages such as relative weaker fabrication reproducibility and mechanical stability comparing with the bare solid electrodes (Svorc et al 1997; Mailley et al 2003) which greatly limit the practical utility of enzymatic assays and probes. Moreover, the binder is nonconducting, which to some extent weakens the electrochemical response of the sensor.

Ionic liquid modified carbon paste electrode (IL-CPE) is a new kind of working electrode prepared by using ionic liquid (IL) as a binder and a modifier. Due to the specific properties of IL such as high chemical and thermal stabilities, negligible vapour pressure, high ionic conductivity, wide electrochemical windows, low toxicity and the ability to dissolve a wide range of organic and inorganic compounds (Liu et al 2005a, b; Pandey 2006), IL-CPEs were demonstrated to exhibit advantages including wide electrochemical windows, inherent electrocatalytic ability and antifouling ability (Wei and Ivaska 2008). Because of their high ionic conductivity and wide electrochemical windows, ILs have been used in electrochemistry and electroanalysis. Compton et al (2004) and Endres (2004) have reviewed the recent progress of RTILs in electrochemistry. Recently, Wang et al (2007) have shown that it is possible to fabricate an IL-carbon paste (CP) biosensor with low background current via 
mixing the paste with paraffin oil 'a non-conductive binder' which tends to decrease the background current and hence improve the sensor response. Liu and coworkers $(2005 \mathrm{a}, \mathrm{b})$ also fabricated an imidazolium-based ionic liquid modified carbon paste electrode, and the presence of ionic liquids caused an increase in the sensitivity of the response toward to nitrite detection (Liu et al 2005a, b). Safavi et al (2007) investigated the electrochemical oxidation of phenolic compounds on an IL-CPE, which exhibited higher stability than commonly used working electrodes. IL-CPE can also be used as the substrate electrode for further modification with redox proteins or nanoparticles, which exhibited many new characteristics and potential applications (Sun et al 2009).

In this paper, an IL, 1-methyl-3-butylimidazolium bromide ([MBIB]), was used as binder for manufacturing the modified carbon paste electrode. IL-CPE electrode was prepared with mixing graphite, parafin oil, ionic liquid and horseradish peroxidase.

\section{Experimental}

\subsection{Apparatus}

In the experiments PalmSens potentiostat (Netherlands), a three-electrodes system from $\mathrm{CH}$ Instruments (USA) that contains, a CHI 111 model $\mathrm{Ag} / \mathrm{AgCl}$ reference electrode and a CHI 115 model platinum wire counter electrode, Gilson $\mathrm{P} 100$ and $\mathrm{P} 1000$ automatic pipettes (France), Yellow-Line magnetic stirrer (Germany) and Nuve model thermostat (TR) were used.

\subsection{Chemicals and reagents}

HRP (EC 1.11.1.7), paraffin oil, potassium ferricyanide, hydrogen peroxide and graphite powder and all other chemicals were purchased from Sigma Chemical. The ionic liquid 1-methyl-3-butylimidazolium bromide ([MBIB]) was kindly prepared by the Chemistry Research Laboratory at Ege University according to earlier study (Tasci et al 2012). All the chemicals were of high-purity grade and used as purchased without further purification.

\subsection{Electrode fabrication}

The required amount of the ionic liquid or parafin oil was mixed using pestle and mortar with the required amount of graphite. This ionic liquid modified carbon paste was tightly packed into a cavity $(3.3 \mathrm{~mm}$ diameter) of a glass tube and the electrical contact was established via copper wire. Then $2 \mathrm{mg}$ of horseradish peroxidase was added and the paste was mixed for $10 \mathrm{~min}$. Prior to use, the surface of the carbon paste electrode was polished with weighing paper.

\subsection{Procedure}

Measurements were carried out with potassium ferricyanide in a phosphate buffer $(0.05 \mathrm{M}, \mathrm{pH} 7)$ containing $5 \mathrm{mM} \mathrm{Fe}(\mathrm{CN})_{6}^{3-/ 4-}$ supporting electrolyte medium for amperometric and cyclic voltammetry measurements. Amperometric detection was made under the potential of $-0.15 \mathrm{~V}$, whereas cyclic voltammetry experiments was made between the potential of -0.6 and $0.6 \mathrm{~V}$. In the former, the desired working potential was applied and transient currents were allowed to decay to a steady-state value.

\section{Results and discussion}

\subsection{Effect of ionic liquid on modified electrode}

In order to detect the effect of ionic liquid on the modified electrode some cyclic voltammetric experiments were done by using the modified CPE electrodes with ionic liquid and without ionic liquid in the presence of $\mathrm{Fe}(\mathrm{CN})_{6}^{3-/ 4-}$ redox couple. A pair of redox peaks were observed for $\mathrm{Fe}(\mathrm{CN})_{6}^{3-/ 4-}$ on a $\mathrm{CPE}$ (figure $1(\mathrm{~A})$, curve a and figure $1(\mathrm{~B})$, curve a). Oxidation peak potential $\left(E_{\mathrm{pa}}\right)$ is about $+0 \cdot 305 \mathrm{~V}$, reduction peak potential $\left(E_{\mathrm{pc}}\right)$ is about $-0.103 \mathrm{~V}$ and $\Delta E_{\mathrm{p}}$ is $0.408 \mathrm{~V}$. On the other hand, a pair of redox peaks at different potentials were observed by using CPE with ionic liquid (figure 1(A), curves b, c, d and e). Oxidation peak potential $\left(E_{\mathrm{pa}}\right)$ is about $0.146 \mathrm{~V}$ and reduction peak potential $\left(E_{\mathrm{pc}}\right)$ is about $-0.05 \mathrm{~V}$ and $\Delta E_{\mathrm{p}}$ is $0 \cdot 196 \mathrm{~V}$ for $(\mathrm{c})$. Also, the peak current $\left(I_{\mathrm{p}}\right)$ at IL-CPE were much larger than about 15.57 times of that at CPE. It can be observed that the background current increased with an increase in the ionic liquid content. As previously reported in the literature (Maleki et al 2006), the addition of ILs to a carbon paste electrode modifies the microstructure of the paste and the charge transfer resistance decreases and charge transfer rate increases, because of the higher conductivity of the electrode containing the ionic liquid. An increase in the ionic liquid content resulted in increasing peak-to-peak separation. The most useful electrochemical results could be obtained by using IL-CPE prepared by 10/20/70 ratio. In addition the best and smooth electrode surface was obtained by using the same ratio. So, the best ratio of ionic liquid was chosen to be $10 \%$.

Figure 2(A) shows CV responses of IL-CPE in $5 \mathrm{mM}$ $\mathrm{Fe}(\mathrm{CN})_{6}^{3-14-}$ with scan rates from 10 to $100 \mathrm{mV} \mathrm{s}^{-1}$. There was a good linear relationship between peak current and the square root of scan rates, which showed a typical diffusion-controlled electrochemical behaviour.

\subsection{Effect of enzyme amount on biosensor responses}

In order to optimize the biosensor, several experimental parameters were investigated for the use with cyclic 

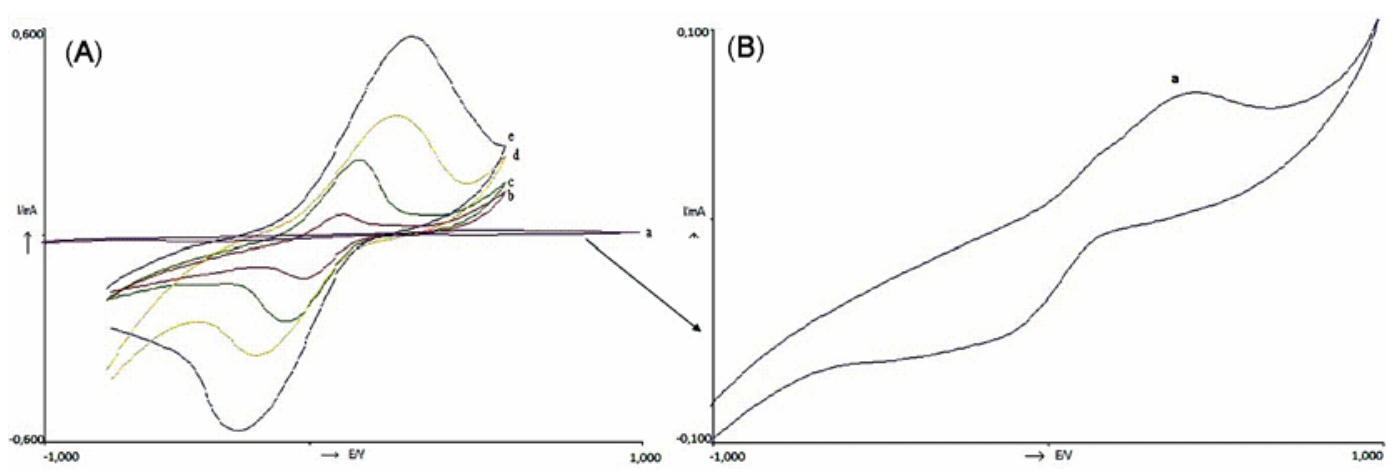

Figure 1. CVs obtained from different ratios of IL/parafin oil/graphite: (a) 0/30/70, (b) 5/25/70, (c) 10/20/70, (d) 15/15/70, (e) 20/10/70 for (A); (a) 0/30/70 for (B), respectively. Conditions: 0.05 M phosphate buffer ( $\mathrm{pH} \mathrm{7)}$ containing $5 \mathrm{mM}$ potassium ferricyanide, scan rate $50 \mathrm{mV} / \mathrm{s}$ and potentials were referred to $\mathrm{Ag} / \mathrm{AgCl}$ reference electrode. Amount of HRP were kept constant to be $2 \mathrm{mg}$, respectively.
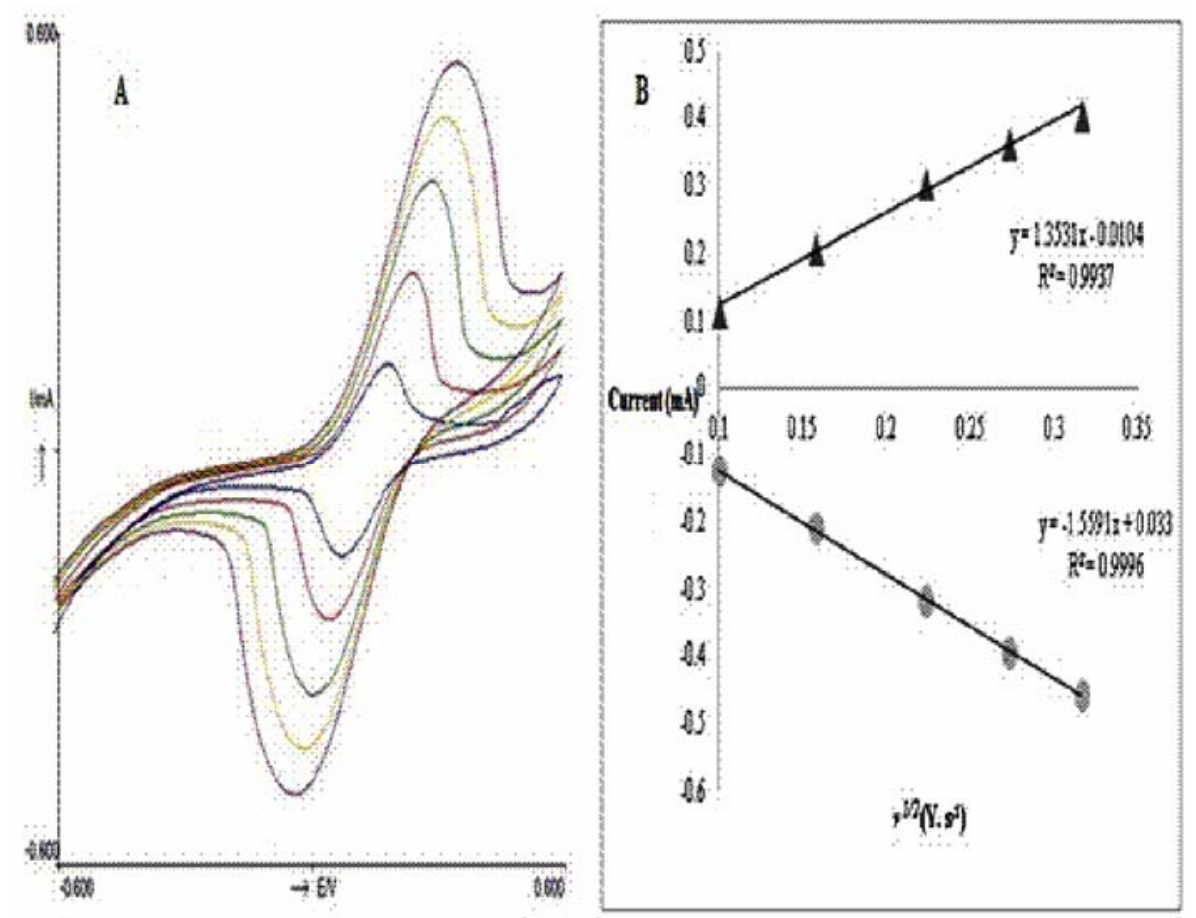

Figure 2. (A) $\mathrm{CVs}$ of IL-CPE at different scan rates (from inside to outside): 0.01, $0 \cdot 025,0 \cdot 05,0 \cdot 075,0 \cdot 1 \mathrm{~V} \mathrm{~s}^{-1}$, respectively. (B) Plot of cathodic and anodic peak currents vs scan rate $\left(v^{1 / 2}\right)$. Conditions: $0.05 \mathrm{M}$ phosphate buffer $(\mathrm{pH} 7)$ containing $5 \mathrm{mM}$ potassium ferricyanide and potentials were referred to $\mathrm{Ag} / \mathrm{AgCl}$ reference electrode. Amount of HRP and ratio of IL/parafin oil/graphite were kept constant to be $2 \mathrm{mg}$ and 10/20/70, respectively.

voltammetry. Initially, to detect the effect of enzyme amount, 1, 2 and $3 \mathrm{mg}$ (113 unit $\mathrm{mg}^{-1}$ ) of peroxidase were used in electrodes with a composition of $70: 20: 10$ (w/w/w) graphite powder: parafin oil : ionic liquid. From the results, higher biosensor responses and more acceptable calibration curves were achieved when biosensor was used, that contained $2 \mathrm{mg}$ horseradish peroxidase. When enzyme amount was used to be $1 \mathrm{mg}$, biosensor responses were decreased and when enzyme amount was used to be $3 \mathrm{mg}$, biosensor responses were increased but calibration curves were decreased because of diffusion barrier occurrence.

\subsection{Amperometric response of developed $\mathrm{H}_{2} \mathrm{O}_{2}$ biosensor}

Amperometric response of IL-CPE to $\mathrm{H}_{2} \mathrm{O}_{2}$ was investigated at different applied potentials between $-0 \cdot 3$ and $0 \cdot 5 \mathrm{~V}$. The most suitable and highest responses were obtained at $-0.15 \mathrm{~V}$. Figure $3(\mathrm{~A})$ shows amperometric 


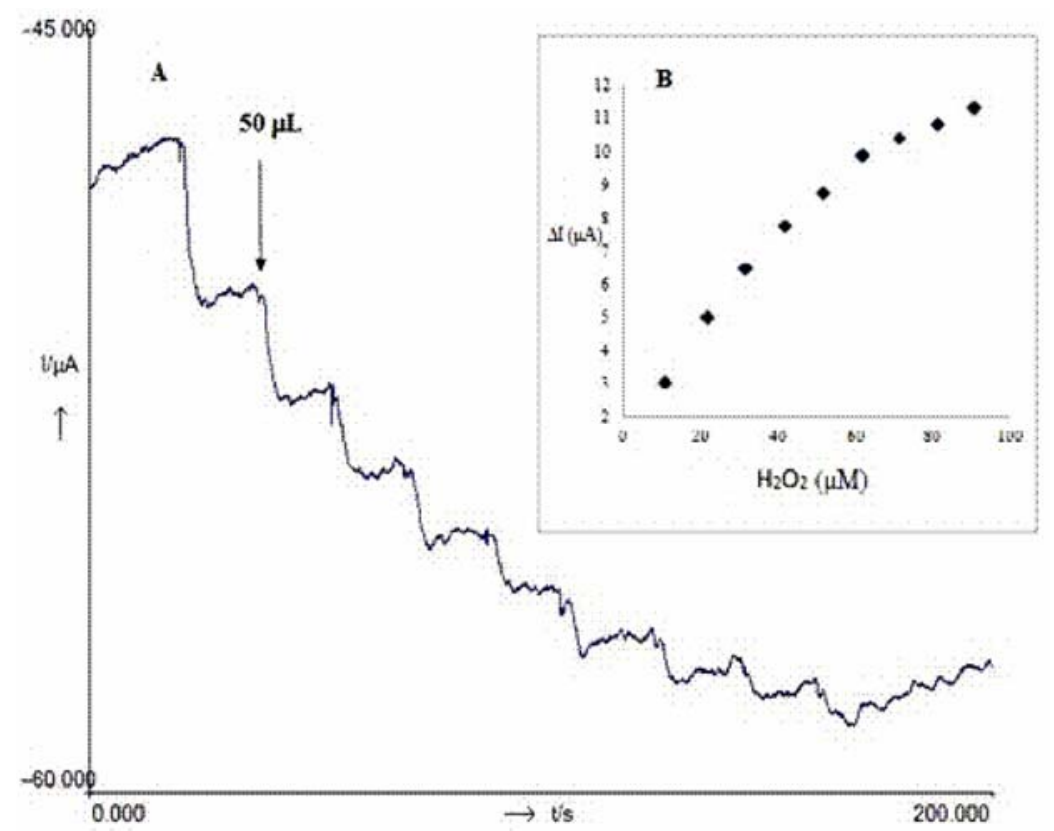

Figure 3. Typical amperometric response of fabricated biosensor to successive addition of $\mathrm{H}_{2} \mathrm{O}_{2}$ in a stirred $0.05 \mathrm{M}$ PBS $(\mathrm{pH}$ 7) containing $5 \mathrm{mM}$ potassium ferricyanide. Applied potential was $-0 \cdot 15 \mathrm{~V}$ vs $\mathrm{Ag} / \mathrm{AgCl}$. (A) Amperometric response of $50 \mu \mathrm{L}$ successive addition of $1 \mathrm{mM} \mathrm{H}_{2} \mathrm{O}_{2}$ and (B) calibration curve between current and concentration of $\mathrm{H}_{2} \mathrm{O}_{2}$. Amount of HRP and ratio of IL/parafin oil/graphite were kept constant to be $2 \mathrm{mg}$ and $10 / 20 / 70$, respectively.

responses of $\mathrm{IL}-\mathrm{CPE}$ to successive addition of $\mathrm{H}_{2} \mathrm{O}_{2}$ in $0 \cdot 05 \mathrm{M}$ PBS ( $\mathrm{pH} \mathrm{7)}$ containing $5 \mathrm{mM} \mathrm{Fe}(\mathrm{CN})_{6}^{3-14}$. The biosensor responded rapidly when $\mathrm{H}_{2} \mathrm{O}_{2}$ was added to the stirring PBS and steady-state current could be obtained within $2 \mathrm{~s}$. The inset (figure 3B) displayed calibration curve of the amperometric response of the biosensor to the concentration of $\mathrm{H}_{2} \mathrm{O}_{2}$. The linear range of the developed biosensor for the determination of $\mathrm{H}_{2} \mathrm{O}_{2}$ was found to be $1 \times 10^{-5}$ $1 \times 10^{-4} \mathrm{M}$ and a correlation coefficient of $0.981(n=9)$.

\subsection{Optimization of experimental conditions}

The effect of the $\mathrm{pH}$, from 6 to 8 on the biosensor response in $0.05 \mathrm{M}$ PBS (pH 7) containing $5 \mathrm{mM} \mathrm{Fe}(\mathrm{CN})_{6}^{3-/ 4-}$ and $5 \times 10^{-5} \mathrm{M} \mathrm{H}_{2} \mathrm{O}_{2}$ solution was also investigated. The highest current was obtained at $\mathrm{pH} 7$, in agreement with the results reported for other studies using horseradish peroxidase (Lei et al 2004; Garcia et al 2007). In addition, the effect of the temperature from 20 to $40{ }^{\circ} \mathrm{C}$ was investigated. The best results was obtained at $30^{\circ} \mathrm{C}$. Therefore, a $\mathrm{pH}$ value of 7 and temperature $30{ }^{\circ} \mathrm{C}$ were used in further experiments.

\subsection{Linear range of biosensor}

For the determination of a linear range for $\mathrm{H}_{2} \mathrm{O}_{2}$, cyclic voltammetry and also amperometric methods were used.
According to the results obtained from both methods, responses of the biosensor depend linearly on $\mathrm{H}_{2} \mathrm{O}_{2}$ concentration between 10 and $100 \mu \mathrm{M}$. The cyclic voltammograms indicated that when concentrations of $\mathrm{H}_{2} \mathrm{O}_{2}$ were increased, anodic peak current of the biosensor increased correlating at the oxidation potential of $\mathrm{K}_{3} \mathrm{Fe}(\mathrm{CN})_{6}$ whereas cathodic peak current of the biosensor decreased reduction potential of $\mathrm{K}_{3} \mathrm{Fe}(\mathrm{CN})_{6}$. From the cyclic voltammograms, it can be said that $\mathrm{K}_{3} \mathrm{Fe}(\mathrm{CN})_{6}$ is an effective mediator in the regeneration of the enzyme.

Figure 4 shows amperometric responses of separate additions of $\mathrm{H}_{2} \mathrm{O}_{2}$ at $-0 \cdot 15 \mathrm{~V}$ potential. From the figure, it can be said that addition of $\mathrm{H}_{2} \mathrm{O}_{2}$ into reaction cell decreased linearly with $\mathrm{H}_{2} \mathrm{O}_{2}$ concentration. Detection limits of the biosensor were found to be $3.98 \mu \mathrm{M}$ for amperometric measurements. This result also supported the amperometric results showed in figure 3.

\subsection{Reproducibility, stability and interference effects of some substances}

The concentration of $5 \times 10^{-4} \mathrm{M} \mathrm{H}_{2} \mathrm{O}_{2}$ was measured consecutively for 7 times and average value, standard deviation (SD) and coefficients of variation (CV\%) were calculated to be $5.4 \times 10^{-4} \mathrm{M}, 0.031,4.2 \%$, respectively. So, it can be said that biosensor showed a good reproducibility for the determination of $\mathrm{H}_{2} \mathrm{O}_{2}$. 


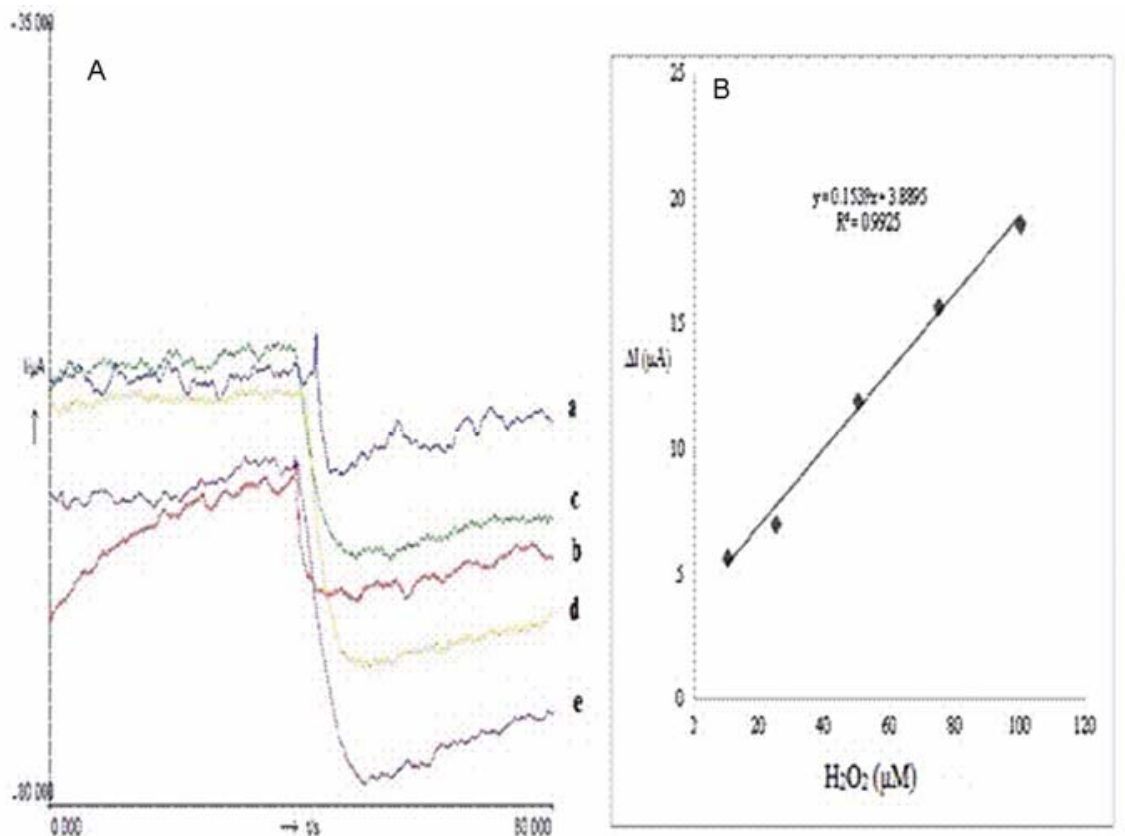

Figure 4. Typical amperometric responses of biosensor in a stirred 0.05 M PBS ( $\mathrm{pH}$ 7) containing $5 \mathrm{mM}$ potassium ferricyanide. Applied potential was $-0.15 \mathrm{~V}$ vs $\mathrm{Ag} / \mathrm{AgCl}$. (A) Amperometric response of $10 \mu \mathrm{M}$ (a), $25 \mu \mathrm{M}$ (b), $50 \mu \mathrm{M}$ (c), $75 \mu \mathrm{M}$ (d), $100 \mu \mathrm{M} \mathrm{H}_{2} \mathrm{O}_{2}$ (e) and (B) calibration curve between the current and concentration of $\mathrm{H}_{2} \mathrm{O}_{2}$. Amount of HRP and ratio of IL/parafin oil/graphite were kept constant to be $2 \mathrm{mg}$ and 10/20/70, respectively.

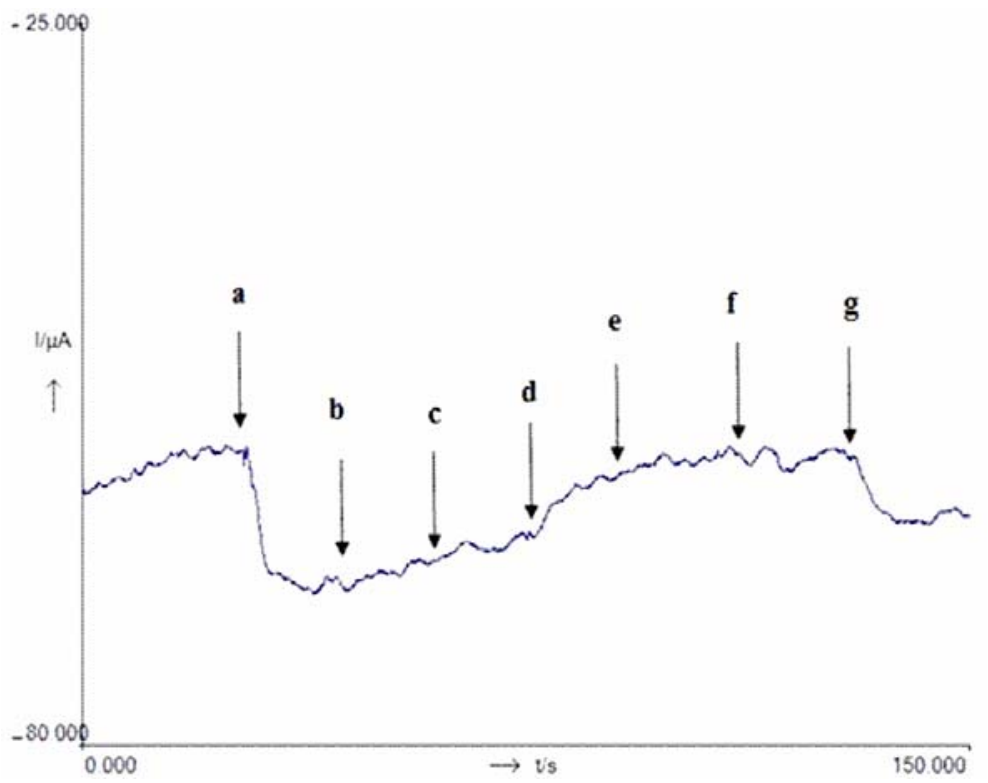

Figure 5. Substrate selectivity of IL-CPE hydrogen peroxide (a), Dglucose (b), D-fructose (c), L-ascorbic acid (d), L-glutamic acid (e), L-aspartic acid (f) and hydrogen peroxide (g) in 0.05 M PBS (pH 7) containing $5 \mathrm{mM}$ potassium ferricyanide. Concentration of all substances is $50 \mu \mathrm{M}$. Amount of HRP and ratio of $\mathrm{IL} /$ parafin oil/graphite were kept constant to be $2 \mathrm{mg}$ and 10/20/70, respectively.

The storage stability of the biosensor has been studied over a period of 2 months. The biosensor was stored at $4{ }^{\circ} \mathrm{C}$ when not in use. The biosensor lost only $7 \%$ of the initial response after 2 weeks and maintained more than $80 \%$ of the initial value after storage for one month. It lost $50 \%$ of the initial response after two months. 
Table 1. Comparison of $\mathrm{H}_{2} \mathrm{O}_{2}$ biosensor based on HRP.

\begin{tabular}{lcccl}
\hline Electrode type & Linear range & Response time $(\mathrm{s})$ & Detection limit $(\mu \mathrm{M})$ & Reference \\
\hline GCE/FBCS & $35-2000 \mu \mathrm{M}$ & 20 & $15 \cdot 0$ & Garcia et al $(2007)$ \\
GCE/P(GMA-co-VFc) & $2-30 \mathrm{mM}$ & 4 & $2 \cdot 60$ & Senel et al $(2010)$ \\
Au/SA-HRP & $7-4100 \mu \mathrm{M}$ & - & $1 \cdot 80$ & Liu et al $(2009)$ \\
GCE/DDAB-HRP & $1-4.0 \mathrm{mM}$ & 5 & - & Tang et al $(2003)$ \\
CCE/nano Au-HRP & $12 \cdot 2-1100 \mu \mathrm{M}$ & $<8$ & $6 \cdot 10$ & Lei et al $(2004)$ \\
IL-CPE-HRP & $10-100 \mu \mathrm{M}$ & 2 & $3 \cdot 98$ & This work \\
\hline
\end{tabular}

GCE, glassy carbon electrode; $\mathrm{P}(\mathrm{GMA}-\mathrm{co}-\mathrm{VFc})$ poly(glycidyl methacrylate-co-vinylferrocene); FBCS, ferrocene branched chitosan; PEGDGE: polyethylene glycol diglycidyl ether; SA, sodium alginate; CCE, carbon ceramic electrode; HRP, horseradish peroxidase; DDAB, didodecyldimethylammonium bromide.

Anti-interference ability of the biosensor was also studied. For this purpose $5 \mu \mathrm{M}$ concentration of D-glucose, Dfructose, L-ascorbic acid, L-glutamic acid, L-aspartic acid (figure 5). We can see only the addition of ascorbic acid increased current $20 \%$ in comparison with $\mathrm{H}_{2} \mathrm{O}_{2}$. It was expected because of its universal interference capacity.

From table 1, it can be told that our proposed biosensor shows great performance in terms of response time and detection limit and it shows acceptable linear range for $\mathrm{H}_{2} \mathrm{O}_{2}$.

\section{Conclusions}

In our work, we have illustrated the ionic liquid (1-methyl-3-butylimidazolium bromide ([MBIB]) which can be used to prepare attractive composite electrodes for amperometric detection of hydrogen peroxide based on peroxidase enzyme. Comparing with $\mathrm{CPE}$ to IL-CPE, when parafin oil only used as the binder decreases the high background current. However, the addition of the ionic liquids has several advantages such as a higher sensitivity, a wider linear dynamic range, high conductivity and higher stability ( $\mathrm{pH}$, thermal and storage). Peroxidase can contain a heme cofactor in its active site, or alternate redox-active cysteine or selenocysteine residues. The nature of the electron donor is dependent on the structure of the enzyme. Horseradish peroxidase can use a variety of organic compounds to be electron donors and acceptors. It has an accessible active site and many compounds can reach the site of the reaction. From the experimental results, it is obvious that the ionic liquid used in the biosensor preparation serves to be an attractive compound for the enzymatic reaction of peroxidase enzyme.

\section{References}

Compton R G, Buzzeo M C and Evans R G 2004 Chem. Phys. Chem. 51106
Chen X, Ruan C, Kong J and Deng J 2000 Anal. Chim. Acta 41289

Endres F 2004 Z. Phys. Chem. 218255

Gao F X, Yuan R, Chai Y Q, Tang M Y, Cao S R and Chen S H 2007 Coll. Surf. A: Physicochem. Eng. Aspects 295 223

Garcia A, Peniche-Covas C, Chico B, Simpson B K and Villalonga R 2007 Macromol. Biosci. 7435

Kulys J 1999 Biosens. Bioelectron. 14473

Lei C, Hu S, Gao N, Shen G and Yu R 2004 Bioelectrochemistry 6533

Liu C, Guo X and Yuan R 2009 J. Mol. Catal. B60 151

Liu H T, He P, Li Z Y, Sun C Y, Shi L H, Liu Y, Zhu G Y and Li J H 2005a Electrochem. Commun. 71357

Liu J F, Jiang G B and Jönsson J A 2005b Trends Anal. Chem. 2420

Liu Y, Yuan R and Chai Y Q 2006 Sens. Actuators B115 109

Maleki N, Safavi A and Tajabadi F 2006 Anal. Chem. 78 3820

Mailley P, Cummings E A, Mailley S C, Eggins B R, McAdams E and Cosnier S 2003 Anal. Chem. 755422

Pandey S 2006 Anal. Chim. Acta 55638

Safavi A, Maleki N and Tajabadi F 2007 Analyst 13254

Senel M, Cevik E and Abasiyanik F 2010 Sens. Actuators B145 445

Sun W, Li X Q, Qin P and Jiao K 2009 J. Phys. Chem. C113 11294

Svorc J, Miertu S, Katrlik J and Stred'ansk M 1997 Anal. Chem. 692086

Tang J, Wang B, Wu Z, Han X, Dang S and Wang E 2003 Biosens. Bioelectron. 18867

Tasci Z, Kunduracioglu A, Kani I and Çetinkaya B 2012 Chem. Cat. Chem. 4831

Wang J and Lu F 1998 J. Am. Chem. Soc. 1201049

Wang S, Chen T, Zhang Z and Pang, D 2007 Electrochem. Commun. 91337

Wei D and Ivaska A 2008 Anal. Chim. Acta 607126

Xiao Y, Ju H X and Chen H Y 2000 Anal. Biochem. 278 22

Xu Y X, Wang F, Chen X X and Hu S S 2006 Talanta 70 651 